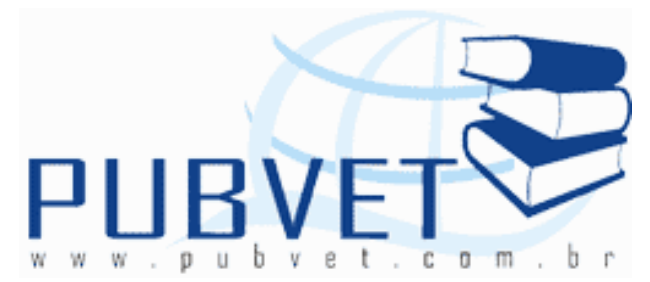

PUBVET, Publicações em Medicina Veterinária e Zootecnia.

\title{
Desempenho de bezerros pós-desmama em dieta de grão de milho inteiro
}

Priscila Zambalde Lasmar ${ }^{1}$, Rafaella Cristina Machado de Melo ${ }^{2}$, Luciene Lignani Bitencourt $^{3}$, Sancho Siécola Júnior ${ }^{4}$, José Ricardo Martins Silva ${ }^{5}$, Marcos Neves Pereira ${ }^{6}$

${ }^{1}$ Zootecnista, Assistência Técnica Nata, Itabuna, BA;

2Zootecnista, Patrocínio, MG;

${ }^{3}$ Médica Veterinária, Estudante de Doutorado do Departamento de Zootecnia, Universidade Federal de Lavras, MG;

${ }^{4}$ Médico Veterinário, Estudante de Mestrado do Departamento de Zootecnia, Universidade Federal de Lavras, MG;

${ }^{5}$ Médico Veterinário, Professor do Instituto Federal do Norte de Minas, Januária, MG;

${ }^{6}$ Professor Adjunto do Departamento de Zootecnia, Universidade Federal de Lavras, MG.

\section{Resumo}

Este ensaio avaliou a utilização de dieta isenta de forragem para bezerros desmamados, baseada em milho maduro não processado. Sete bezerros foram desmamados aos 67 dias de idade e em seguida alocados a uma dieta composta exclusivamente por concentrado baseado em grão inteiro de milho e farelo de soja por 56 dias. O ganho diário de peso foi 0,901 $\pm 0,213 \mathrm{~kg}$ e o 
LASMAR, P.Z. et al. Desempenho de bezerros pós-desmama em dieta de grão de milho inteiro. PUBVET, Londrina, V. 5, N. 23, Ed. 170, Art. 1143, 2011.

consumo de matéria seca foi $2,80 \pm 0,32 \mathrm{~kg}$. A eficiência alimentar foi $0,320 \pm$ $0,061 \mathrm{~kg}$ de ganho/ $\mathrm{kg}$ de consumo de matéria seca A digestibilidade aparente da matéria seca no trato digestivo total foi $75,8 \pm 10,7 \%$ do consumido, o consumo como porcentagem do peso vivo foi em média 2,39\% durante a determinação da digestibilidade. O coeficiente de correlação entre o consumo e a digestibilidade foi $-0,70$. A perda fecal de grãos inteiros de milho nas fezes foi $1,03 \%$ do grão ingerido e não se correlacionou à digestibilidade do concentrado. Não foi observado qualquer caso de timpanismo ou distúrbio nos locomotores, sugerindo que acidose ruminal não foi um problema nestes animais. Bezerros na fase pós-desmama alimentados exclusivamente com concentrado baseado em grão inteiro de milho tiveram desempenho zootécnico satisfatório.

Palavras-chave: ganho de peso, digestibilidade, desempenho

\section{Performance of post-weaning calves on a diet of whole corn grain}

\section{Abstract}

This trial evaluated the use of diet with no forage for weaned calves, based on no processed mature corn. Seven calves were weaned at 67 days of age and then allocated to a diet composed exclusively of concentrate based on whole corn grain and soybean meal for 56 days. The daily body weight gain was $0.901 \pm .213 \mathrm{~kg}$ and dry matter intake was $2.80 \pm 0.32 \mathrm{~kg}$. Feed efficiency was $0.320 \pm 0061 \mathrm{~kg}$ of gain $/ \mathrm{kg}$ of dry matter intake. Digestibility of dry matter in the total digestive tract was $75.8 \pm 10.7 \%$ of intake, intake as a percentage of body weight was on average $2.39 \%$ during the determination of digestibility. The correlation coefficient between the intake and digestibility was -0.70 . The fecal loss of whole corn seeds in feces was $1.03 \%$ of the grain consumed and was not correlated to the digestibility of concentrate. There was no case of bloat or disturbance in locomotion, suggesting that ruminal acidosis was not a problem in these animals. Performance of post-weaning calves fed 
LASMAR, P.Z. et al. Desempenho de bezerros pós-desmama em dieta de grão de milho inteiro. PUBVET, Londrina, V. 5, N. 23, Ed. 170, Art. 1143, 2011.

exclusively concentrate based on whole grain corn performance was satisfactory.

Keywords: body weight gain, digestibility, performance

\section{INTRODUÇÃO}

Ruminantes têm a capacidade de digerir carboidratos fibrosos devido à existência de simbiose entre o animal e os microorganismos ruminais (Van Soest, 1994). Um teor mínimo de fibra longa na dieta tem sido recomendado para manter a saúde e a longevidade de vacas leiteiras, devido ao efeito deste tipo de nutriente sobre a motilidade do rúmen, a atividade mastigatória e a produção de saliva (Armentano e Pereira, 1997). Entretanto, dietas compostas exclusivamente por grãos têm sido utilizadas para animais de corte (Murphy et al., 1994; Pordomingo et al. 2002). Nestes casos, grãos de milho não processados são utilizados como fonte energética, uma maneira de reduzir a velocidade de degradação do amido no rúmen e induzir alguma atividade mastigatória em dietas isentas de fibra longa (Owens et al., 1997).

Possíveis vantagens da utilização de dietas isentas de forragem e com milho não processado são de natureza econômica e operacional. Dietas compostas apenas por grãos eliminam o trabalho agronômico de produção de forragens ou a necessidade de compra, transporte e estocagem destes alimentos. Eliminam também a necessidade de processamento de grãos para fornecimento aos animais.

O objetivo deste ensaio foi avaliar o desempenho de bezerros alimentados com dieta composta exclusivamente por concentrado baseado em milho maduro não processado fornecido após a fase de aleitamento. $O$ intuito não foi comparar esta estratégia alimentar a um tratamento controle. 
LASMAR, P.Z. et al. Desempenho de bezerros pós-desmama em dieta de grão de milho inteiro.

PUBVET, Londrina, V. 5, N. 23, Ed. 170, Art. 1143, 2011.

\section{MATERIAL E MÉTODOS}

O ensaio foi conduzido no Setor de Bovinocultura de Leite do Departamento de Zootecnia da Universidade Federal de Lavras (UFLA). O período de coleta de dados foi de 13 de julho a 23 de dezembro de 2007 . Os animais foram instalados em bezerreiros individuais a partir de 7 a 15 dias de idade, as instalações eram de piso de cimento e cama de serragem. Sete bezerros foram utilizados: um 3/4 Pardo Suíço x Holandês, um 1/2 Pardo Suíço $x$ Holandês, um $7 / 8$ Holandês $\times$ Gir, um $3 / 4$ Holandês $x$ Jersey e três Holandeses.

Os animais foram alimentados durante a fase de aleitamento com quatro litros de leite integral, sendo dois litros fornecidos de manhã e dois litros à tarde, concentrado de aleitamento (Tab. 1) e água à vontade. O consumo de concentrado foi mensurado diariamente. O desmame ocorreu quando o consumo diário de concentrado foi de $1 \mathrm{~kg}$ por três dias consecutivos. A idade dos animais à desmama foi $66,7 \pm 12,8$ dias (média \pm desvio padrão).

Tabela 1. Composição do concentrado de aleitamento em ingredientes e nutrientes

\begin{tabular}{lc}
\hline & $\%$ da MS \\
\hline Milho maduro moído fino & 53,9 \\
Farelo de trigo & 19,4 \\
Farelo de soja $_{\text {Mineral }^{1}}$ & 19,6 \\
\end{tabular}

Proteína bruta 18,6

Fibra em detergente neutro $\quad 18,0$

${ }^{1}$ Mineral: Ca 23,5\%, P 4,5\%, S 2,3\%, Na 8,018\%, Zn 0,238\%, Cu 0,063\%, $\mathrm{Fe}$ 0,118\%, F 0,045\%, Mn 0,031\%, Co 0,003\%, I 0,004\%, Se 0,001\%, niacina 0,333\%, Vit. A $70000 \mathrm{UI} / \mathrm{kg}$, Vit. D 5000UI/kg, Vit. E $15 \mathrm{UI} / \mathrm{kg}$ e promotor de eficiência alimentar 0,135\%.

Após o desmame os animais passaram por um período de sete dias de transição do concentrado de aleitamento para o concentrado baseado em grão inteiro de milho (Tab. 2). Durante a transição o consumo diário do concentrado 
LASMAR, P.Z. et al. Desempenho de bezerros pós-desmama em dieta de grão de milho inteiro. PUBVET, Londrina, V. 5, N. 23, Ed. 170, Art. 1143, 2011.

de aleitamento foi fixado em $1 \mathrm{~kg}$ e o concentrado com milho inteiro foi fornecido à vontade. Os animais receberam a dieta com milho inteiro ad libitum por 56 dias. Mistura mineral foi fornecida à vontade no cocho de minerais. Os animais foram pesados semanalmente e o consumo de concentrado foi monitorado diariamente entre os dias 29 e 56 de fornecimento da dieta com milho inteiro.

Tabela 2. Composição do concentrado baseado em grão inteiro de milho em ingredientes e nutrientes

\begin{tabular}{lc}
\hline & $\%$ da MS \\
\hline INGREDIENTES & \\
Milho maduro inteiro & 88,9 \\
Farelo de soja & 11,1 \\
& \\
NUTRIENTES & 14,3 \\
Proteína Bruta & 10,4 \\
Fibra em detergente & \\
neutro & \\
\hline
\end{tabular}

O ganho de peso foi calculado pela inclinação da reta descrevendo a mudança linear no peso vivo entre os dias 28 e 56 de fornecimento do concentrado. O coeficiente de determinação destas regressões foi em média 0,95, variando de 0,88 a 0,98. A eficiência de conversão alimentar neste mesmo período foi mensurada pelo ganho de peso médio dividido pelo consumo médio de matéria seca.

A mensuração da produção fecal foi realizada no dia 56 por coleta total de fezes durante 24 horas ininterruptas para determinação da digestibilidade aparente da matéria seca no trato digestivo total. Foi formada uma amostra composta das fezes de cada bezerro. As amostras foram mantidas a $-20^{\circ} \mathrm{C}$ até a desidratação em estufa ventilada por 72 horas a $60^{\circ} \mathrm{C}$. As amostras fecais pré-secas e a dieta consumida foram trituradas em peneira de $1 \mathrm{~mm}$ para posterior desidratação a $105^{\circ} \mathrm{C}$ por 24 horas. Para cálculo da digestibilidade foi considerado o consumo de matéria seca de cada animal nos dias 54, 55 e 56. No mesmo período, a excreção fecal de grãos inteiros foi quantificada por 
LASMAR, P.Z. et al. Desempenho de bezerros pós-desmama em dieta de grão de milho inteiro. PUBVET, Londrina, V. 5, N. 23, Ed. 170, Art. 1143, 2011.

mensuração do número de grãos de milho inteiro por unidade concentrado e nas amostras composta pré-secas de fezes.

\section{RESULTADOS E DISCUSSÃO}

O ganho diário de peso foi $0,901 \pm 0,213 \mathrm{~kg}$ e o aumento no peso corporal foi linear ao longo do período avaliado (Fig. 1). Este pode ser considerado um ganho de peso alto para animais leiteiros nesta faixa etária. Liziere et al. (2002) e Cunha et al. (2007), trabalharam com bezerros mestiços Holandês x Zebu e Nussio et al. (2003) com bezerros Holandês em dietas estritamente de concentrado e observaram um ganho de peso diário de 0,521 $\mathrm{kg}$ (9 a 10 semanas de idade), 0,553 kg (9 a 10 semanas de idade) e 0,393 \pm $0,039 \mathrm{~kg}$ (6 a 12 semanas), respectivamente.

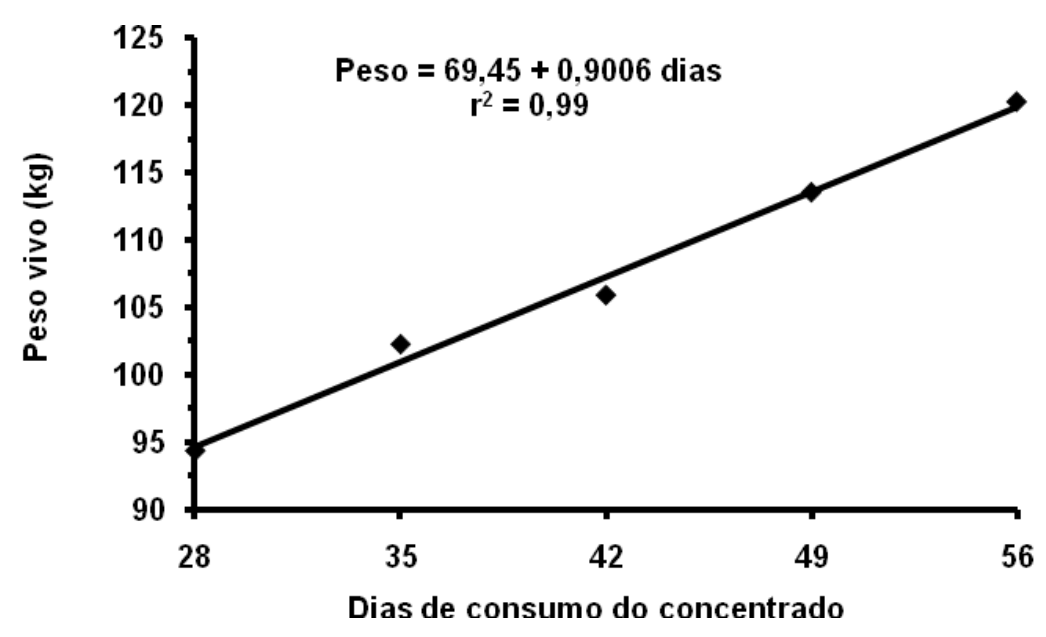

Figura 1. Peso vivo entre os dias 28 e 56 de fornecimento de dieta composta exclusivamente por concentrado baseado em grão de milho inteiro.

O consumo de matéria seca entre os dias 29 e 56 foi $2,80 \pm 0,32 \mathrm{~kg}$, não mostrando tendência de aumento ao longo do tempo (Fig. 2). A eficiência alimentar foi $0,320 \pm 0,061 \mathrm{~kg}$ de ganho/ $\mathrm{kg}$ do consumo de matéria seca. $O$ 
LASMAR, P.Z. et al. Desempenho de bezerros pós-desmama em dieta de grão de milho inteiro. PUBVET, Londrina, V. 5, N. 23, Ed. 170, Art. 1143, 2011.

valor obtido na eficiência alimentar nesta fase foi semelhante aos obtidos no trabalho de Lizieire et al. (2002), trabalhando com bezerros alimentados com dieta contendo concentrado comercial e concentrado comercial mais feno de alfafa, ao redor de 0,4 em ambos os tratamentos. Cunha et al. (2007) também obteve conversão de 0,350 $\pm 0,008$ para bezerros mestiços alimentados com ração comercial.

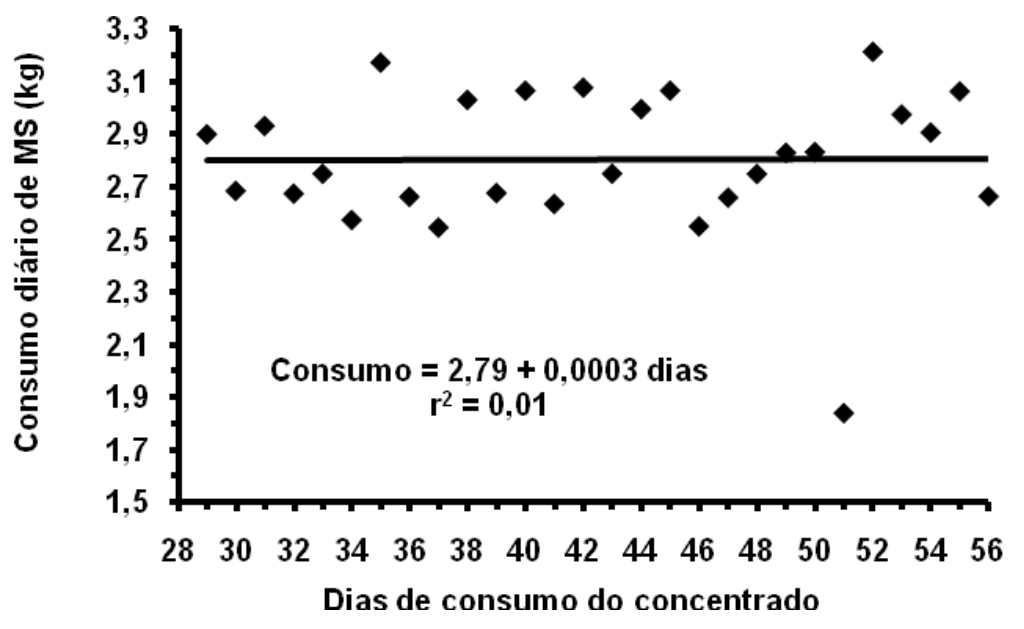

Figura 2. Consumo de matéria seca entre os dias 29 e 56 de fornecimento de dieta composta exclusivamente por concentrado baseado em grão de milho inteiro.

Estes valores de conversão alimentar são inferiores aos observados em frangos de corte, ao redor de 0,649 (Bertechini, 2006), mas são semelhantes aos observados em fases da engorda de suínos. Suínos com peso vivo entre 20 e $50 \mathrm{~kg}$ têm conversão ao redor de 0,368 e animais entre 50 e $110 \mathrm{~kg}$ têm conversão ao redor de 0,264 (Nutrient..., 1988). Promover ganho de peso em bezerros com dieta exclusiva de grão parece ser mais ineficiente que engordar aves, mas pode competir em eficiência com a suinocultura. Este fato pode ser explicado pela menor de perda de metano como proporção da energia digestível quando ruminantes são alimentados com dieta exclusiva de grãos, já que estas dietas são capazes de induzir queda na relação entre acetato e propionato na fermentação ruminal (Murphy et al., 1994). 
LASMAR, P.Z. et al. Desempenho de bezerros pós-desmama em dieta de grão de milho inteiro. PUBVET, Londrina, V. 5, N. 23, Ed. 170, Art. 1143, 2011.

O consumo de concentrado durante a mensuração da produção fecal para determinação da digestibilidade aparente da matéria seca no trato digestivo total foi ao redor de $2,4 \%$ do peso vivo (Tab. 3 ). Os valores de consumo e digestibilidade para o animal 3 foram numericamente inferiores aos observados para os outros animais. Nenhuma causa aparente para esta discrepância foi evidenciada. Após a remoção do animal 3 do banco de dados, a correlação entre o consumo como porcentagem do peso vivo e a digestibilidade aparente da matéria seca foi $-0,70(P<0,01)$, provavelmente relacionada à maior taxa de passagem da digesta ou a menor eficiência de digestão do amido em maior nível de consumo. A digestibilidade foi $79,4 \pm$ $5,8 \%$ do ingerido quando o animal 3 foi retirado do banco de dados, semelhante ao valor de NDT para milho grosseiramente moído (Nutrient..., 2001).

Tabela 3. Consumo diário de matéria seca nos dias 54, 55 e 56 (CMS), digestibilidade aparente da matéria seca no trato digestivo total (D), grãos de milho inteiros nas fezes como proporção dos grãos ingeridos (\%G), peso vivo no dia 56 (Peso) e consumo como porcentagem do peso vivo (\%CMS) por animal consumindo dieta composta exclusivamente por concentrado baseado em grão de milho inteiro.

\begin{tabular}{lccccc}
\hline Bezerro & $\begin{array}{c}\text { CMS } \\
(\mathrm{kg})\end{array}$ & $\mathrm{D}(\%)$ & $\% \mathrm{G}$ & Peso $(\mathrm{kg})$ & $\%$ CMS \\
\hline 1 & 2,35 & 84,9 & 0,11 & 98,0 & 2,40 \\
2 & 3,47 & 75,5 & 0,80 & 134,8 & 2,57 \\
3 & 2,13 & 54,6 & 0,18 & 107,8 & 1,97 \\
4 & 3,19 & 81,9 & 1,74 & 136,0 & 2,35 \\
5 & 2,76 & 79,8 & 3,01 & 123,8 & 2,23 \\
6 & 3,22 & 84,3 & 0,61 & 130,0 & 2,48 \\
7 & 3,09 & 69,9 & 0,75 & 111,4 & 2,71 \\
& & & & & \\
Média & 2,88 & 75,8 & 1,03 & 120,3 & 2,39 \\
DP & 0,49 & 10,7 & 1,03 & 14,7 & 0,24 \\
\hline
\end{tabular}

A digestibilidade não se correlacionou significativamente à proporção do grão inteiro ingerido excretado nas fezes. A perda fecal de grãos inteiros foi aparentemente baixa. Pordomingo et al. (2002) observaram perda fecal de 
LASMAR, P.Z. et al. Desempenho de bezerros pós-desmama em dieta de grão de milho inteiro. PUBVET, Londrina, V. 5, N. 23, Ed. 170, Art. 1143, 2011.

grãos inteiros variando de 7 a $9 \%$ do ingerido em bezerros com peso vivo inicial de $155 \mathrm{~kg}$ e alimentados com dieta baseada em milho inteiro e isenta de forragem. Estes autores observaram que a perda de grãos inteiros nas fezes aumentou levemente em animais mais velhos $(269 \mathrm{~kg})$. A baixa faixa etária dos animais utilizados neste ensaio pode ser uma explicação plausível para a baixa excreção fecal de grãos inteiros aqui observada. Diferenças no tipo de milho utilizado são uma explicação pouco provável para este fato, já que, apesar de não ter sido mensurada a vitreosidade ou a densidade dos grãos, o milho utilizado neste trabalho era do tipo flint, e portanto de baixa digestibilidade (Corrêa et al., 2002).

Não foi observado qualquer caso de timpanismo ou distúrbio nos locomotores, sugerindo que acidose ruminal clínica não foi um problema nestes animais (Nocek, 1997). Apesar da ausência total de fibra longa na dieta, os animais apresentaram atividade mastigatória, mostrando a capacidade do grão inteiro de milho de manter funções fisiológicas em ruminantes normalmente atribuídas à efetividade física da fibra dietética (Armentano e Pereira, 1997). O efeito de dietas similares, fornecidas por período de tempo superior ao aqui utilizado, requer avaliação.

\section{CONCLUSÃO}

Bezerros na fase pós-desmama alimentados exclusivamente com concentrado baseado em grão inteiro de milho tiveram desempenho zootécnico satisfatório. A utilização destas dietas pode ser interessante quando o intuito é avaliar o efeito das características do milho sobre o desempenho e a eficiência digestiva de ruminantes, sem o confundir com outros ingredientes dietéticos.

\section{REFERÊNCIAS BIBLIOGRÁFICAS}

ARMENTANO, L.E; PEREIRA, M.N. Measuring the effectiveness of fiber by animal response trial. J. Dairy Sci., v.80, p.1416-1425, 1997. 
BERTECHINI, A.G. Nutrição de Monogástricos. Lavras: Editora UFLA, 2006. 301p.

CÔRREA, C.E.S.; SHAVER, R.D.; PEREIRA, M.N.; LAUER, J.G.; KOHN, K. Relationship between corn vitreousness and ruminal in situ starch degradability. J. Dairy Sci., v.85, p.3008-3012, 2002.

CUNHA, D.N.F.V.; CAMPOS, O.F.; PEREIRA, J.C.; PIRES, M.F.A.; LIZIEIRE, R.S.; MARTUSCELLO, J.A. Desempenho, variáveis fisiológicas e comportamento de bezerros mantidos em diferentes instalações: época chuvosa. Rev. Bras. Zootec., v.36, p.1140-1146, 2007.

LIZIEIRE, R.S.; CUNHA, D.N.F.V.; MARTUSCELLO, J.A; CAMPOS, O.F. Fornecimento de volumoso para bezerros pré-ruminantes. Ciência Rural, v.32, p.835-840, 2002.

MURPHY, T.A.; FLUHARTY, F.L.; LOERCH, S.C. The influence of intake level and corn processing on digestibility and ruminal metabolism in steers fed all-concentrate diets. J. Anim. Sci., v.72, p.1608-1615, 1994.

NUTRIENT requirements of dairy cattle. 7.ed. Washington: National Academy Press, 2001. $381 \mathrm{p}$.

NUTRIENT requirements of swine. 9.ed. Washington: National Academy Press, 1988. 381 p.

NOCEK, J.E. Bovine acidosis: implications on laminitis. J. Dairy Sci., v.80, p.1005-1028, 1997.

NUSSIO, C.M.B.; SANTOS, F.A.P.; ZOPOLLATTO, M.; PIRES, A.V.; MORAIS, J.B. Processamento de milho (floculado vs. laminado a vapor) e adição de monensina para bezerras leiteiras, pré e pós-desmama precoce. Rev. Bras. Zootec., v.32, p.229-239, 2003.

OWENS, F.N.; SECRIST, D.S.; HILL, W.J.; GILL, D.R. The effect of grain source and grain processing on performance of feedlot cattle: A review. J. Anim. Sci., v.75, p.868-879, 1997.

PORDOMINGO, A.J.; JONAS, O.; ADRA, M.; JUAN, N.A.; AZCÁRATE, M.P. Evaluación de dietas basadas em grano entero, sin fibra larga, para engorde de bovinos a corral. Rev. Invest. Agropec., v.31, p.1-23, 2002.

VAN SOEST, P. J. Nutritional ecology of the ruminant. 2.ed. Ithaca: Cornell University, 1994. 